\title{
Maximal oxygen uptake, total metabolic energy expenditure, and energy cost in swimmers with physical disabilities
}

Wellington G. Feitosa, Tiago M. Barbosa, Ricardo De A. Correia \& Flávio A. De S Castro

To cite this article: Wellington G. Feitosa, Tiago M. Barbosa, Ricardo De A. Correia \& Flávio A. De $S$ Castro (2019): Maximal oxygen uptake, total metabolic energy expenditure, and energy cost in swimmers with physical disabilities, International Journal of Performance Analysis in Sport

To link to this article: https://doi.org/10.1080/24748668.2019.1631053

曲 Published online: 14 Jun 2019.

Submit your article to this journal

View Crossmark data $\nearrow$ 


\title{
Maximal oxygen uptake, total metabolic energy expenditure, and energy cost in swimmers with physical disabilities
}

\author{
Wellington G. Feitosa $\mathbb{D}^{\mathrm{a}, \mathrm{b}}$, Tiago M. Barbosa $\mathbb{( D}^{\mathrm{c}, \mathrm{d}, \mathrm{e}}$, Ricardo De A. Correia (iD) \\ and Flávio A. De S Castro (iD) \\ ${ }^{a}$ Aquatic Sports Reseach Group, Universidade Federal do Rio Grande do Sul, Porto Alegre, Brasil; ${ }^{b}$ Centro \\ de Ciências da Saúde, Universidade Estadual do Ceará, Fortaleza, Brasil; 'Department Physical Education \& \\ Sports Science, Nanyang Technological University, Singapore, Singapore; dDepartment of Sport Sciences, \\ School of Education, Polytechnic Institute of Bragança, Bragança, Portugal; ' $\mathrm{CIDESD}$, Research Centre in \\ Sports Health and Human Develop, Vila Real, Portugal
}

\begin{abstract}
The purpose of this study was to assess the maximum oxygen uptake $\left(\mathrm{V}_{2 \text { max }}\right)$, the total metabolic energy expenditure $(\dot{E}$ tot $)$, and the energy cost $(C)$ measured as the speed of $\mathrm{VO}_{2 \max }$ in swimmers with physical impairments. Eleven swimmers performed an Nx200$\mathrm{m}$ front crawl test from a low to all-out speed and data were obtained at maximum aerobic power. The oxygen uptake was measured breath-by-breath by a telemetric gas exchange system. The Ėtot was calculated from the aerobic and anaerobic pathways at maximal intensity. The $C$ was obtained by the ratio of the $\dot{E}$ tot and the mean swimming speed. The $\mathrm{VO}_{2 \text { max }}$ was $38.2 \pm 8.3 \mathrm{~mL} . \mathrm{kg}$. $\mathrm{min}^{-1}$, the Ėtot was $191.9 \pm 51.7 \mathrm{~kJ}$, and the $C$ was $0.8 \pm 0.2 \mathrm{~kJ} \cdot \mathrm{m}^{-1}$. The energy contribution of the aerobic pathway was higher $(p<0.001)$ than that of both the anaerobic pathways, which were similar $(p>0.05)$. There was no gender effect on the results of the energy contributions ( $p>0.05)$. The anaerobic lactic pathway contribution was higher in male than in female swimmers $(p<0.05)$. The $\dot{V} O_{2 \max }$ and $C$ were higher in swimmers who were less affected by physical impairment. The energy contribution of the aerobic pathways was similar for males and females.
\end{abstract}

\section{ARTICLE HISTORY}

Received 3 April 2019

Accepted 10 June 2019

\section{KEYWORDS}

Swimming; aerobic power; energetics; anaerobic contribution; physiological profile

\section{Introduction}

The physiological parameters related to performance are effectively developed as a function of each athlete's potentialities and singularities (Barbosa et al., 2010). Among the important physiological parameters related to human locomotion used in the sports performance assessment are the maximum aerobic power $\left(\dot{\mathrm{V}}_{2 \max }\right)$, the total metabolic energy expenditure (Etot), and the energy cost $(C)$ (Fernandes et al., 2006; Morris, Osborne, Shephard, Jenkins, \& Skinner, 2017). These physiological

CONTACT Wellington G. Feitosa wellington.feitosa@uece.br $\Theta$ Centro Natatório da Escola de educação Física, Fisioterapia e Dança.Universidade Federal do Rio Grande do Sul, Felizardo, 750, Jardim Botânico, Porto Alegre,.90690200,.Brazil

The study was approved by the local Ethics Committee (no. 2.274.037) and followed the orders of the Declaration of Helsinki.

(c) 2019 Cardiff Metropolitan University 
parameters might differ between swimmers with physical disabilities and those without, between male and female swimmers, and among classes. Swimmers with physical disabilities are classified into sports classes by the impact of an eligible impairment on their ability to perform the specific and fundamental tasks of the sport (classes S1 to S10 from the highest to the lowest impact) (International Paralympic Committee [IPC]. World Para Swimming: classification rules and regulations, International Paralympic Committee [IPC], 2017). According to different cases of disabilities and their relationship with aerobic power, expressions of energy metabolic rates and $C$ can provide useful information for training strategies and performance improvement of these swimmers.

Estimates of the Etot and $C$ have been calculated from oxygen uptake and blood lactate (Barbosa, Fernandes, Keskinen, \& Vilas-Boas, 2008; Gonjo et al., 2018). Therefore, the Etot is the result of the sum of the energy supplied by the aerobic, anaerobic lactic and alactic pathways. In turn, the $C$ is a bioenergetic predictor of the performance of human locomotion (Barbosa et al., 2010; Di Prampero, 1986) and can be described according to Equation 1:

$$
C=\frac{\dot{E} t o t}{v}
$$

where $C$ is the energy cost and $v$ represents the speed executed in a given locomotion task. The $C$ represents the amount of metabolic energy expended in transporting the body mass of the participant over a unit of distance (Capelli, Pendergast, \& Termin, 1998). Thus, competitive swimmers seek to travel a given distance as quickly as possible. In this sense, the average swimming speed exercised is an important performance factor and is associated with the ability to overcome the drag (Barbosa et al., 2008). The drag is one of the main $C$ determinants (Pendergast et al., 2006) and the technical level can be analysed by the swim speed (Barbosa et al., 2010). In addition, the increase in $C$ is related to the increase in swimming speed and drag in the aquatic environment (Toussaint \& Hollander, 1994). Among the morphological disadvantages that can increase drag and affect the speed of locomotion in swimming are, for example, deformities or amputations of limbs, hemiplegia, and paraplegia (Oh, Burkett, Osborough, Formosa, \& Payton, 2013). These morphological characteristics also influence different physiological expressions whose scientific knowledge can be deepened (Bentley, Phillips, McNaughton, \& Batterham, 2002; de Souza et al., 2016).

Some studies have investigated the relationship between oxygen uptake, Etot, and $C$ of non-disabled swimmers (Barbosa et al., 2008; Bentley et al., 2005; Capelli et al., 1998; Zamparo, Capelli, \& Pendergast, 2011). However, few studies have addressed the physiological profile of swimmers with physical impairments (de Souza et al., 2016; Rodrigues Junior, De Jesus, Corredeira, Daly, \& Fernandes, 2016). In one of the studies with people with physical disabilities, $C$ was assessed in people who used wheelchairs (Conger \& Bassett, 2011). However, we found no study reporting the $\dot{\mathrm{VO}_{2 m a x}}$ Etot, and $C$ of competitive swimmers with physical impairments. Although there are studies on the contributions of energy pathways in intermittent tests for non-disabled swimmers (Ribeiro et al., 2015; Sousa, Vilas-Boas, \& Fernandes, 2014; Troup, 1991), the energy contributions in addition to the $\dot{\mathrm{V}} \mathrm{O}_{2}, \dot{E}$ tot, and $C$ measured as speed of $\dot{\mathrm{V}} \mathrm{O}_{2 \text { max }}$ 
$\left(\mathrm{v}^{\mathrm{V}} \mathrm{O}_{2 \max }\right)$ for swimmers with physical impairments are still unknown. The study of these physiological variables and $\mathrm{vVO}_{2 \max }$ can contribute to the compilation of data to aid decisions on appropriate actions before and after performance tests.

Through these evaluations it is possible to quantify the Etot and $C$ of swimmers needed for a particular task, which enables adjustments to be made to the training programme to improve performance. In addition, such investigations explore the possible relationships between characteristics of physical disability and their possible effects on these physiological variables.

Thus, the purpose of this study was to assess the $\dot{\mathrm{V}}_{2 \max }$, the $\dot{E} t o t$, and $C$ measured as $\mathrm{vVO}_{2 \max }$ in swimmers with physical impairments, comparing: (i) swimmers grouped by sports classes and (ii) males and females. We formulated three hypotheses: (i) the highest values of $\dot{\mathrm{VO}}_{2 \max }$ occur in swimmers with the lowest impact of physical disability, even though the $\dot{E} t o t$ and $C$ measured as $\mathrm{vV}_{2 \max }$ are highest in swimmers with the highest impact of physical disability; and (ii) male swimmers have higher values of Etot, $C$, and energy contribution (aerobic and anaerobic) than female swimmers.

\section{Methods}

\subsection{Participants}

Seven male and four female swimmers (age $32.4 \pm 12.4$ years; height $1.73 \pm 0.85 \mathrm{~m}$; body mass $67.2 \pm 9.9 \mathrm{~kg}$; training background $6.4 \pm 3.7$ years) participated in the study. The main disabilities were: hemiplegia, muscle stiffness and poor motor coordination $(\mathrm{n}=1$, sport class S5), spinal cord injury $(\mathrm{n}=3$, T11-L1, T11-T12, and L1-L2, sport classes S5, S7, and S8), one arm near the shoulder amputation $(n=1$, sport class S8), one forearm amputation $(\mathrm{n}=1$, sport class S9), one lower limb amputation near the hip $(\mathrm{n}=3$, sport class S9), congenital crooked foot sequelae and low ankle mobility $(\mathrm{n}=1$, sport class S9), and amputation slightly below the knee $(\mathrm{n}=1$, sport class S10). Swimmers with at least 2 years of experience in swimming competitions at any stage (regional, national, or international) and who had any physical impairments participated in this research. All of the participants had training sessions at least five times per week and swam $20 \mathrm{~km}$ per week. The exclusion criterion was the presence of contraindications for physical tests at maximum intensity, e.g. mental retardation, congenital or atherosclerotic heart disease, and atlantoaxial instability or any restrictive injury for training and competition.

The study was approved by the local Ethics Committee and followed the orders of the Declaration of Helsinki. The aims and methods were thoroughly explained to the participants who gave their written consent.

\subsection{Experimental approach}

The swimmers had anthropometric measurements of body mass $\left(\mathrm{SECA}^{\circ} 813\right.$, resolution of $0.1 \mathrm{~kg}$, Hamburg, Germany) and height (SANNY, Personal Caprice, resolution of $0.1 \mathrm{~cm}$, São Paulo, Brazil) recorded. Then, they were familiarised over two sessions with the equipment: the Aquatrainer snorkel (Cosmed, Rome, Italy) and GBK2 pacer (GBK 


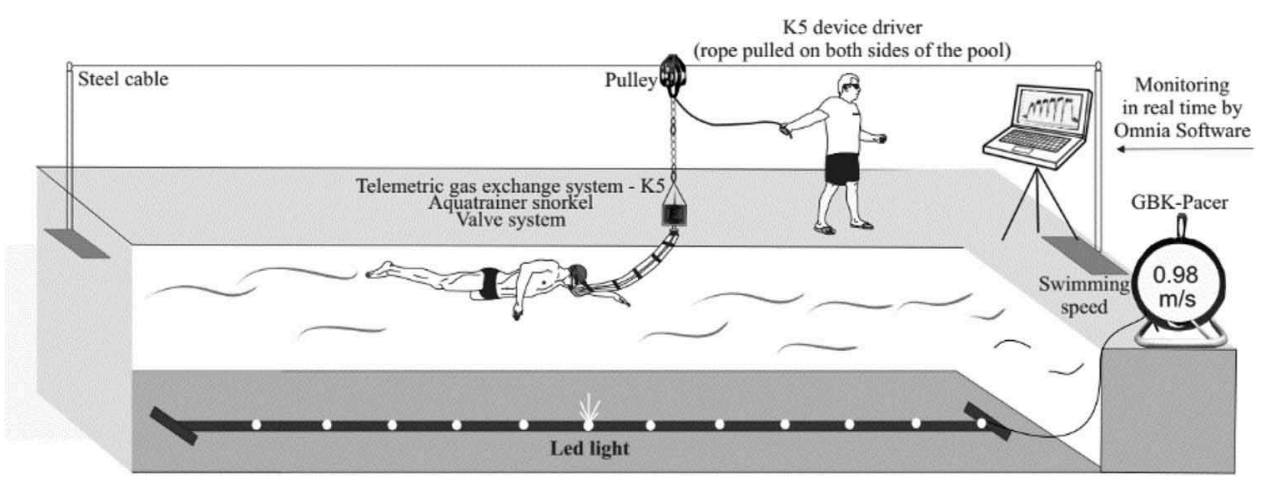

Figure 1. Physiological data collection set-up over the Nx200-m protocol.

Electronics, Aveiro, Portugal), and the procedures for physiological data collection in an intermittent incremental test, oxygen uptake $\left(\dot{\mathrm{VO}}_{2}\right)$, heart rate $(\mathrm{HR})$, rate of perceived exertion (RPE), and blood lactate concentration (La). All swimmers had previously used snorkels in their regular training programme. A session was held to familiarised themselves with GBK2 pacer (Fernandes et al., 2008; Keskinen \& Keskinen, 1999). Before the tests and measurements, the swimmers were asked not to take part in moderate to vigorous physical activity for at least 24 hours.

The tests were carried out individually in a $25-\mathrm{m}$ length indoor swimming pool. The setup of the data collection is portrayed in Figure 1. A warm-up of 600-m was developed according to the experience and level of conditioning of the swimmers (swimming at low-moderate intensity in 200-m freestyle, 200-m with a conventional snorkel, and 200-m with an Aquatrainer snorkel). A time trial (200-m with encouragements for the best effort) was conducted to decide the speed of the incremental intermittent test $(\mathrm{Nx} 200-\mathrm{m})$. The rest period of 24 hours occurred between the $200-\mathrm{m}$ and $\mathrm{Nx} 200-\mathrm{m}$ tests.

The intermittent incremental test $(\mathrm{Nx} 200-\mathrm{m})$ had speed increases of $0.05 \mathrm{~m} . \mathrm{s}^{-1}$ with 30 second rest intervals between each $200-\mathrm{m}$ stage. The swimming speed during the Nx200-m was individually controlled by the GBK2 pacer (Keskinen \& Keskinen, 1999). The first programmed speed on the pacer was determined by the average speed of the $200-\mathrm{m}$ test decreased by $0.25 \mathrm{~m} . \mathrm{s}^{-1}$. However, the $\dot{\mathrm{VO}}_{2 \max }$ was achieved in the $4^{\text {th }}, 5^{\text {th }}$, and $6^{\text {th }}$ stages for different swimmers.

\subsection{Data collection}

The concentration of gases was measured by the continuous collection of expired gases, supported by a telemetric gas exchange in a breath-by-breath system (K5; Cosmed) and respiratory valve system (Aquatrainer; Cosmed) that represent low hydrodynamic resistance (Keskinen, Rodriguez, \& Keskinen, 2003; Ribeiro et al., 2016). The gas analysis system was calibrated before each collection. The device for respiratory gas capture along with the snorkel were suspended at a height of 2-m. A double pulley system and a pair of steel cords passed above the entire length of the pool. The double pulley along with the $\mathrm{K} 5$ and Aquatrainer snorkel were pulled on ropes by two people 
(a rope on each side of the pool), minimising disruption to the movements of the swimmer (Figure 1).

In order to minimise the noise arising from the acquisition of gases by breath by breath through the ergospirometric system, errant breaths, e.g. coughing, speaking, and swallowing, that do not represent the desired breath were excluded. Values between the mean \pm four standard deviations (Ozyener, Rossiter, Ward, \& Whipp, 2001) were considered. The $\mathrm{V}_{2}$ data were smoothed by using a moving average of three breaths (Fernandes et al., 2008) in average periods of five seconds (Sousa et al., 2010), which increased the validity of the estimated parameter. The $\dot{\mathrm{V}} \mathrm{O}_{2 \max }$ was obtained at the minimum swimming speed above which $\mathrm{V}_{2}$ failed to increase further (Poole \& Jones, 2017). It was in accordance with primary and secondary criteria (Howley, Bassett, \& Welch, 1995): (i) the occurrence of a plateau in $\mathrm{V}_{2}$ (variation less than 2.1 mL.kg.min ${ }^{-1}$ ) despite increasing swimming speed; (ii) elevated La ( $\geq 8 \mathrm{mmol} . \mathrm{L})$; and (iii) a high respiratory exchange rate $(\mathrm{r} \geq 1.0)$, high heart rate (HR $>90 \%$ of [220 - age in years]), and high rate of perceived exertion (visually controlled and case by case).

The La level was measured using an Accutrend Plus portable meter and reagent strips (Accutrend; Roche, Mannheim, Germany), HR was measured in beats.min ${ }^{-1}$ using a Polar V800 cardiac monitor with H10 Bluetooth transmitter (Polar Electro Oy; Kempele, Finland) and RPE on a scale of 15 points (Borg, 1998) was measured at rest, at 30 s intervals, immediately after the NX200-m, and at 1, 3, 5, and 7 minutes after the last swim (Sousa et al., 2014). The HR (beats.min ${ }^{-1}$ ) was converted into a percentage of $\mathrm{HR}$ through the equation [(HRmax-HR swim test).(HRmax) $]^{\star} 100$ (Wilmore \& Costill, 2004). The use of \%HRmax has been recommended for swimmers with different fitness levels and ages to facilitate the interpretation of the results (Pfeiffer, Pivarnik, Womack, Reeves, \& Malina, 2002; Psycharakis, 2011).

The $\dot{E}_{t o t}$ was calculated for the aerobic and anaerobic sources (alactic and lactic) at the $\dot{\mathrm{V}} \mathrm{O}_{2 \max }$ swim speed (at the lowest velocity at which the $\dot{\mathrm{V}} \mathrm{O}_{2 \max }$ was reached, expressed as $\mathrm{v} \mathrm{V}_{2 \mathrm{max}}-\mathrm{m} . \mathrm{s}^{-1}$ ). The $\dot{E}_{\text {tot }}$ was calculated using the net $\dot{\mathrm{VO}}_{2}$, the difference between the value measured at the end of the stage and the rest value, adjusted for body mass (Barbosa et al., 2008; Di Prampero, Pendergast, Wilson, \& Rennie, 1978). The $\dot{\mathrm{VO}}_{2}$ values were determined by the average of the last $60 \mathrm{~s}$ of each stage, except for the $\dot{\mathrm{VO}}_{2 \text { max }}$, which was calculated as already described (Howley et al., 1995). Additionally, the net blood lactate level (the difference between the value measured in each two consecutive stages) was transformed into $\dot{\mathrm{VO}} \mathrm{O}_{2}$ equivalents using a $2.7 \mathrm{mLO}_{2} \cdot \mathrm{kg} \cdot \mathrm{mmol}^{-1}$ constant and by Equation (2) (Di Prampero et al., 1978; Thevelein, Daly, \& Persyn, 1984).

$$
\dot{E} t o t=\mathrm{VO}_{2} \text { net }+(2.7 . \mathrm{La}-\text { net }) . \mathrm{t}
$$

The Etot (aerobic and anaerobic pathways) was expressed in kJ. The anaerobic contribution was calculated as the sum of the energies obtained from the blood lactate concentrations, as estimated from Lab, plus the energy derived from the maximal depletion of phosphocreatine in working muscles. The $t$ represents the duration of the effort (Capelli et al., 1998), Equation (3):

$$
\dot{E} \text { tot anaerobic }=\left(0.418 \mathrm{KJ} * \mathrm{Kg}^{-1}+\mathrm{Lab}\right) \text { body mass }
$$


where $\dot{E}$ tot anaerobic is in kilojoules, body mass of the participant is in kilograms, b is the energy equivalent of the blood lactate concentration, which was assumed to be equal to 0.0689 (kJ.kg.mmol.L ${ }^{-1}$ ) (Di Prampero, 1981), and Lab is the peak blood lactate concentration after exercise above resting (when $\Delta \mathrm{Lab}=1 \mathrm{mmol} . \mathrm{L}^{-1}$, the net amount of metabolic energy released by lactate formation was 0.0689 (kJ.kg.mmol.L ${ }^{-1}$ ) (Di Prampero, 1981). The value of $0.418 \mathrm{~kJ} \cdot \mathrm{kg}^{-1}$ in Equation 2 coincides with the net splitting of $18.5 \mathrm{mmol}$ of phosphocreatine per $\mathrm{kg}$ of wet muscle in a maximally working muscle mass equal to $30 \%$ of the overall body mass (Capelli et al., 1998).

The C of locomotion was calculated by splitting the $\dot{E}_{t o t}$ by swimming speed $(v)$ (Barbosa et al., 2008; Di Prampero, 1986; Zamparo et al., 2005). The speed was obtained from the incremental swimming test at maximal aerobic power (Figueiredo, Zamparo, Sousa, Vilas-Boas, \& Fernandes, 2011). All swimmers were exactly at the speed of the pacer. The cost values were converted into SI units where $1 \mathrm{mLO}_{2}$ is equivalent to $20.1 \mathrm{~J}$ (Minetti, 1998).

\subsection{Statistical analyses}

All statistical analyses were performed using the software IMB SPSS Statistics (version 25.0 for Windows, IBM Corp; Armonk, NY, USA). The Shapiro-Wilk test was used to verify the distribution of the data. Once normality was established, the sample data were described using the mean \pm standard deviation (SD). The percentage difference was calculated for comparisons of the variables between genders. Individual data for sport class and $\mathrm{v}^{\circ} \mathrm{O}_{2 \max }, \dot{\mathrm{V}} \mathrm{O}_{2 \max }, \dot{E}$ tot, and $C$ were also determined. To verify if there was a difference among the energetic pathways (aerobic, anaerobic lactic, and alactic) and gender interaction, a repeated measures ANOVA with a fixed factor (gender) was used, with a Bonferroni test. The sphericity of the data was tested using a Mauchly test ( $\mathrm{p}<0.05)$ and the Epsilom Greenhouse-Geisser correction factor was applied (explained by degrees of freedom). Statistical significance was set at $\mathrm{p}<0.05$. The figures were produced using GraphPad Prism (version 8.00 for Windows, GraphPad Software; La Jolla, California, USA).

\section{Results}

The results were displayed as the mean, standard deviation, and confidence interval for the mean of swimmers with physical impairments at the speed of maximum oxygen uptake for the variables $\left(\dot{\mathrm{VO}_{2 \max }}, \mathrm{La}_{\text {peak }}, \mathrm{C}\right.$, Etot, $\mathrm{HR}_{\max }$, and $\% \mathrm{HR}_{\max }$ ) obtained with $\mathrm{vVO}_{2 \max }$ (Table 1). All of the physiological variables showed low-dispersion. The physiological variables for $\dot{\mathrm{VO}}_{2}$ of rest, $\mathrm{La}$ of rest, and $\mathrm{RPE}$ at the end of the test were, respectively, $4.7 \pm 1.1 \mathrm{~mL} . \mathrm{kg} \cdot \mathrm{min}^{-1}, 2.2 \pm 0.6 \mathrm{mmol} . \mathrm{L}^{-1}$, and $18 \pm 1.9$.

The individual values of $\mathrm{vVO}_{2 \max }, \dot{\mathrm{V}} \mathrm{O}_{2 \max }$, and $C$ for sex and sport class are shown in Figure 2. Female swimmers showed higher values of $\dot{\mathrm{VO}}_{2 \max }$ with physical impairments that had a lower impact on activity. The $C$ of female swimmers was similar among sports classes. The male swimmers had a tendency for higher values of $\dot{\mathrm{VO}}_{2 \text { max }}$ and $C$ with increasing $\mathrm{vVO}_{2 \max }$, except for the sport class S9 (Figure 2).

In the female group, the mean and standard deviation values of $\mathrm{v}_{\mathrm{V}} \mathrm{O}_{2 \max }, \dot{\mathrm{V}} \mathrm{O}_{2 \max }$, and $C$ were, respectively, $0.85 \pm 0.09 \mathrm{~m} . \mathrm{s}^{-1}, 31.0 \pm 4.1 \mathrm{~mL} . \mathrm{kg} . \mathrm{min}^{-1}$, and $0.7 \pm 0.1 \mathrm{~kJ} . \mathrm{m}^{-1}$; whereas 
Table 1. Overall mean, standard-deviation, and confidence interval for the mean of swimmers with physical impairments at the speed of maximum oxygen uptake $(n=11)$.

\begin{tabular}{|c|c|c|}
\hline Variables & Mean \pm SD & 95\% Confidence Interval \\
\hline$v \dot{V} O_{2 \max }\left(\mathrm{m} \cdot \mathrm{s}^{-1}\right)$ & $0.93 \pm 0.16$ & $0.81-1.03$ \\
\hline$\dot{V} O_{2 \max }\left(\mathrm{mL} \cdot \mathrm{kg} \cdot \mathrm{min}^{-1}\right)$ & $38.2 \pm 8.3$ & $32.6-43.8$ \\
\hline $\mathrm{La}_{\text {peak }} \mathrm{mmol} . \mathrm{L}^{-1}$ & $\begin{array}{rl}9.7 & \pm 3.9 \\
0 & 80\end{array}$ & $\begin{array}{r}7.0-12.3 \\
066-0.95\end{array}$ \\
\hline $\begin{array}{l}C\left(\mathrm{~kJ} \cdot \mathrm{m}^{-1}\right) \\
\dot{E} t o t(\mathrm{~kJ})\end{array}$ & $\begin{array}{r}0.80 \pm 0.21 \\
191.9 \pm 51.7\end{array}$ & $157.1-226.7$ \\
\hline $\begin{array}{l}H R_{\max }(\text { beats.min } \\
\left.\% R_{\max }^{-1}\right)\end{array}$ & $\begin{aligned} 167 & \pm 14.3 \\
88.9 & \pm 6.6\end{aligned}$ & $\begin{array}{c}157.3-176.6 \\
84.4-93.4\end{array}$ \\
\hline
\end{tabular}

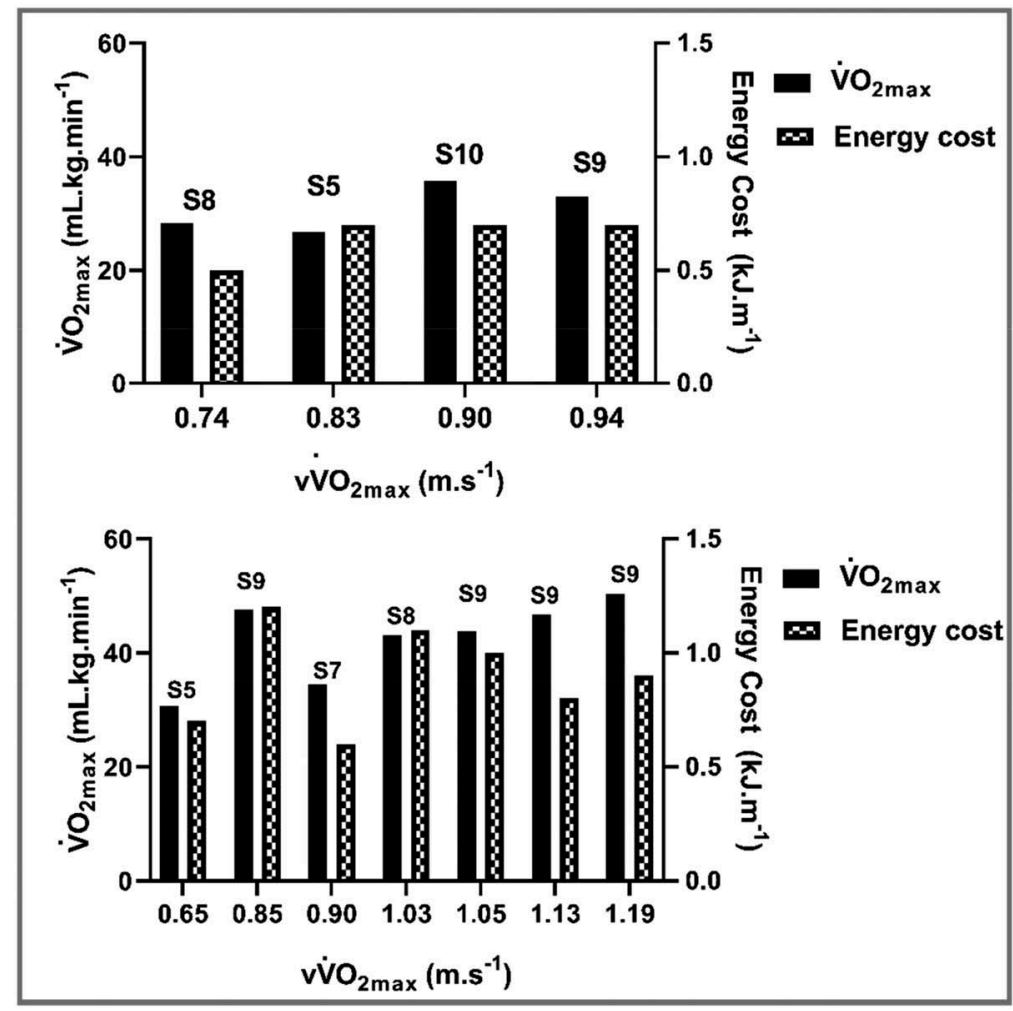

Figure 2. Individual values of $v \dot{V} O_{2 \max }, \dot{V} O_{2 \max }$, and $\mathrm{C}$ of female (top image, $\mathrm{n}=4$ ) and male (bottom image, $\mathrm{n}=7$ ) per sport class. For a description of the sport classes see (International Paralympic Committee [IPC]. World Para Swimming: classification rules and regulations, International Paralympic Committee [IPC], 2017).

in the male group, the $\mathrm{v}^{\circ} O_{2 \max }, \dot{\mathrm{V}}{ }_{2 \max }$, and $C$ were, respectively, $0.97 \pm 0.19 \mathrm{~m} . \mathrm{s}^{-1}$, $42.4 \pm 7.2 \mathrm{~mL} \cdot \mathrm{kg} \cdot \mathrm{min}^{-1}$, and $0.9 \pm 0.2 \mathrm{~kJ} \cdot \mathrm{m}^{-1}$. The percentage difference between the means for males and females for $\mathrm{v}_{\mathrm{V}} \mathrm{O}_{2 \max }, \dot{\mathrm{V}} \mathrm{V}_{2 \max }$, and $C$ was, respectively, $12.2 \%, 27.0 \%$, and $22.2 \%$.

The Etot was $214.0 \pm 47.3 \mathrm{~kJ}$ for males and $153.4 \pm 36.8 \mathrm{~kJ}$ for females (a $28.3 \%$ difference) (Figure 3). The aerobic and anaerobic energy contributions (lactic and alactic) to $\mathrm{vVO}_{2 \max }$ are depicted in Figure 3. The energy contribution of the aerobic 


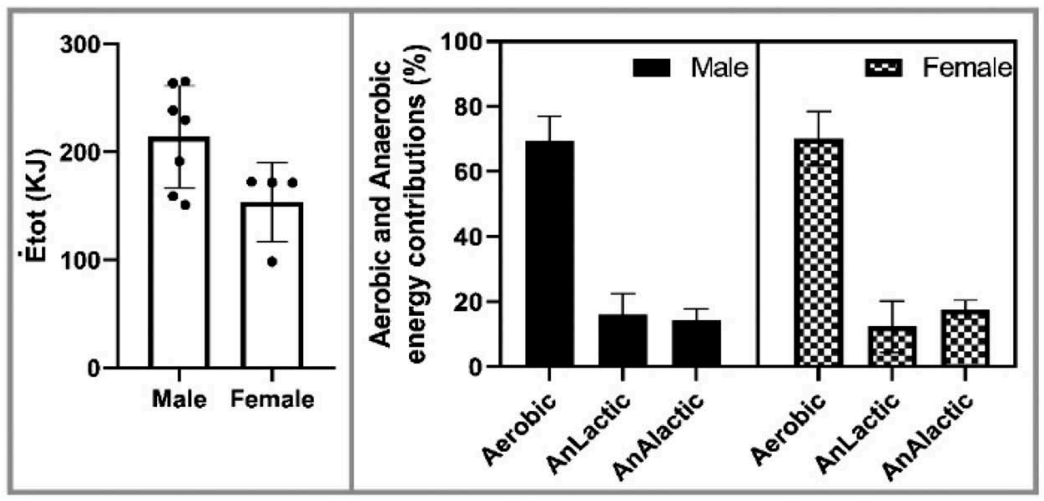

Figure 3. Mean \pm SD of $\dot{E}$ tot and the percentage of aerobic and anaerobic energy (AnLactic $=$ anaerobic lactic and AnAlactic $=$ anaerobic alactic) contributions at $v \dot{V} O_{2 \max }(\mathrm{n}=11)$.

pathway was similar for males $(69.6 \pm 7.3 \%)$ and females $(70.2 \pm 8.1 \%)$. The energy contribution of the anaerobic lactic pathway was higher by $3.8 \%$ for males (16 $\pm 6.4 \%)$ than females $(12.2 \pm 7.8 \%)$. The anaerobic alactic energy contribution for males was $14.3 \pm 3.4 \%$ and females $17.4 \pm 2.8 \%$ (a $3.1 \%$ difference in the mean). The ANOVA showed that there was a distinct effect of the contribution of the energy pathways on swimmers $\left[F(1.29-11.65)=178.9 ; \mathrm{p}<0.001, \eta^{2}=0.95\right]$. The Bonferroni post-hoc test showed that the energy contribution of the aerobic pathway was higher than that of the anaerobic lactic pathway $(\mathrm{p}<0.001)$ and alactic pathway $(\mathrm{p}<0.001)$, however, the anaerobic alactic and lactic pathway energy contributions did not differ to each other $(\mathrm{p}>0.05)$.

\section{Discussion}

This study assessed the $\dot{\mathrm{V}} \mathrm{O}_{2 \max }$, Etot, and $C$ in swimmers with physical impairments. By assigning females to one group and males to another, we demonstrated that the $\mathrm{v} \mathrm{VO}_{2 \max }, \dot{\mathrm{VO}_{2 \max }}, \dot{E}$ tot, and $C$ were higher in the group of male swimmers with physical impairments than the group of females. The energy contribution of the anaerobic lactic pathway was higher for male swimmers whereas the alactic energy contribution was higher for female swimmers.

The highest values of $\dot{\mathrm{VO}}_{2 \max }$ were obtained for swimmers with the lowest impacting physical impairment. Among the physical impairments present in this study were Hemiplegia, Paraplegias, amputation of the arm or forearm, and amputations of the lower limbs. The amount of activated muscle mass directly influences $\dot{\mathrm{VO}}_{2}, \mathrm{La}$, and $\mathrm{HR}$ (Astrand \& Rodahl, 1986; Narang et al., 2012; Saltin, Radegran, Koskolou, \& Roach, 1998). In our investigation, most participants with high $\mathrm{v}^{\mathrm{VO}}{ }_{2 \max }$ reached the highest levels of $\dot{\mathrm{V}}{ }_{2 \max }$ (except for the male sport class $\mathrm{S} 9$ swimmer, $\mathrm{v}_{\mathrm{V}} \mathrm{O}_{2 \max }=0.85 \mathrm{~m} . \mathrm{s}^{-1}$ and $\dot{\mathrm{VO}_{2 \max }}=47.5 \mathrm{~mL} \cdot \mathrm{kg} \cdot \mathrm{min}^{-1}$ ). In addition, there was also a tendency of $\mathrm{v}^{\mathrm{V}} \mathrm{O}_{2 \max }$ and $\dot{\mathrm{V}} \mathrm{O}_{2 \max }$ to be higher in swimmers with physical impairments that had less of an impact. It is possible to relate higher $\mathrm{vV}_{2 \max }$ with better aerobic performance (Di Prampero et al., 1993; Grant, Craig, Wilson, \& Aitchison, 1997), even among participants with 
similar $\dot{\mathrm{V}}_{2 \max }$ rates (Santos et al., 2012). However, in swimmers with physical disabilities it is necessary to take into account the ability to perform the specific and fundamental tasks of the sport (Tweedy \& Vanlandewijck, 2011). Therefore, each physical disability or set of disabilities seem to directly influence the $\mathrm{vVO}_{2 \max }$.

Few studies have been carried out with swimmers with physical disabilities on incremental intermittent tests. When the peak oxygen consumption of Brazilian Paralympic swimmers at $100 \%$ of the athlete's maximum speed of the best result in official competitions $(6 \times 300 \mathrm{~m}$ in front crawl) was assessed, the following values were obtained for each sports class in mL.kg. $\min ^{-1}$ (de Souza et al., 2016): S4 (18.40, female), S5 (35.50, male), S6 (55.80, male), and S7 (37.20, female). In addition, male swimmers with a physical disability $(\mathrm{n}=13)$ obtained the following sports class values for $\mathrm{V}_{2 \max }$ in mL.kg.min ${ }^{-1}(7 \times 200 \mathrm{~m}$ in front crawl) (Rodrigues Junior et al., 2016): S6 (52.1), S7 (41.0), S8 (47.0 $\pm 4.0, \mathrm{n}=4)$, S9 $(48.7 \pm 6.9, \mathrm{n}=6)$, and S10 (35.10). These values are slightly higher than those reported in the present study for: (i) male swimmers presented by sport class, $\mathrm{VO}_{2 \max }$ in $\mathrm{mL} \cdot \mathrm{kg}^{-1} \mathrm{~m}^{-1}$ : S5 (30.6), S7 (34.5), S8 (43), and S9 $(47.1 \pm 2.7, \mathrm{n}=4)$; and (ii) female swimmers presented by sport class, $\dot{\mathrm{VO}}_{2 \max }$ in $\mathrm{mL} . \mathrm{kg}$. $\mathrm{m}^{-1}$ : S5 (26.8), S8 (28.3), S9 (33), and S10 (35.7). Peak oxygen consumption values $\left(31.1 \pm 8.4\right.$ in mL.kg.m $\left.{ }^{-1}, \mathrm{n}=12 ; 33.6 \pm 7.1 \mathrm{~mL} \cdot \mathrm{kg} \cdot \mathrm{m}^{-1}, \mathrm{n}=7\right)$ were also found for handbike athletes with spinal cord injury (T2-T12 injury, paraplegia) in arm cranking maximal incremental test (arm crank ergometer out of water) (Fischer, Figueiredo, \& Ardigo, 2015; Fischer, Tarperi, George, \& Ardigo, 2014). The swimmers with paraplegia ( $\mathrm{n}=3$, T11-L1, T11-T12, and L1-L2) of the current study reached similar values $\left(\mathrm{V}_{2 \max } 31.1 \pm 3.1\right.$ in mL.kg.m $\left.{ }^{-1}\right)$.

The Etot was higher for male swimmers than female swimmers. The duration of exercise performed by male swimmers $(3.63 \pm 0.36$ in decimal minutes) was less than of female swimmers (3.94 \pm 0.54 in decimal minutes), except for two males (one swimmer with paraplegia [4.90 in decimal minutes] and one with amputation of the forearm [3.92 in decimal minutes]). In our study, $v \dot{V} O_{2 \max }$ ranged from 0.6 to $1.1 \mathrm{~m} . \mathrm{s}^{-1}$. In a study of physical disabilities (incremental intermittent test of $7 \times 200 \mathrm{~m}$ ) the speed reached varied similarly from 0.7 to $1.1 \mathrm{~m} . \mathrm{s}^{-1}$ (Rodrigues Junior et al., 2016). However, swimmers with physical disabilities are slower than non-disabled swimmers. Some studies have shown that the velocity of non-disabled swimmers $(\mathrm{n}=8)$ ranged from 0.96 to $1.42 \mathrm{~m} . \mathrm{s}^{-1}$ (Capelli et al., 1998); $1.16 \pm 0.01 \mathrm{~m} . \mathrm{s}^{-1}$ for low-level swimmers $(\mathrm{n}=10)$ and $1.4 \pm 0.06 \mathrm{~m} . \mathrm{s}^{-1}$ for highly trained swimmers $(\mathrm{n}=10)$ (Fernandes et al., 2006). In fact, exercise duration is the major determinant of the energy source ( $\mathrm{Di}$ Prampero, 2003).

The aerobic pathway provided approximately $70 \%$ of energy for both sexes during the repetition in which the maximum aerobic power was reached. The energy contribution of the anaerobic lactic pathway was higher in male swimmers than female swimmers. Conversely, the anaerobic alactic contribution was higher in female swimmers than in males. These energy contributions might be due to the higher muscle mass present in male swimmers than females (Ribeiro et al., 2015; Zamparo et al., 2011). Studies with non-disabled swimmers have shown that during maximal swimming trials they mainly use the aerobic energy source $(61.5 \%)$, followed by energy from the anaerobic lactic (24.7\%) and alactic (13.8\%) pathways (Zamparo et al., 2011). 
Therefore, the results of this investigation are in accordance with the energy contributions of swimmers without physical disabilities for both aerobic (65\%) and the anaerobic pathways (35\%) when swimming 200-m in freestyle (Troup, 1991).

Higher $C$ values were coincided with higher values of aerobic power. The $C$ also rose from S5 to S10 (from the highest to lowest physical impairment to perform specific sports tasks). When exploring the results, we noticed that the swimmer in class S9 reached high values of $\dot{V} O_{2 \max }$ and $C$ despite having a slower swimming speed than the other swimmers. Swimmers can perform better more easily by reducing the $C$ than by increasing Etot (in one of its components, aerobic or anaerobic) (Zamparo et al., 2011). There are a number of possible reasons for this swimmer being less energy-efficient, such as amputation of the forearm resulting in a lower swimming speed than that of other non-disabled upper limbs. However, the male swimmer in sports class S8, who had an amputation of the right arm near the shoulder, showed a higher $\mathrm{vVO}_{2 \text { max }}$ than the male swimmer in sports class S9. The main difference between the two men is possibly their training background in years and technical level (Costa, Bragada, Marinho, Silva, \& Barbosa, 2012).

The physical disability of each swimmer and their anthropometric characteristics, for example, the amount of muscle tissue and adipose tissue, might influence the hydrodynamic ability of female swimmers to perform the motor actions with a lower underwater torque (Zamparo et al., 1996). Therefore, $C$ was higher in male swimmers with disabilities than in female swimmers. In relation to non-disabled swimmers, the literature indicates that female swimmers have a lower $C$ than male swimmers (Chatard, Lavoie, \& Lacour, 1990, 1991; Zamparo, Capelli, Cautero, \& Di Nino, 2000). In freestyle, the $C$ has been reported for elite male swimmers without disabilities to be $0.8 \mathrm{~kJ} . \mathrm{m}^{-1}$ at $1.1 \mathrm{~m} . \mathrm{s}^{-1}$ (Capelli et al., 1998), for low level swimmers $10.9 \pm 1.80 \mathrm{~J} . \mathrm{kg} . \mathrm{m}^{-1}$ at $1.2 \mathrm{~m} . \mathrm{s}^{-1}$, for highly trained swimmers $13.1 \pm 2.3 \mathrm{~J} . \mathrm{kg} . \mathrm{m}^{-1}$ at $1.2 \mathrm{~m} . \mathrm{s}^{-1}$ (Fernandes et al., 2006), and $0.8 \mathrm{KJ} . \mathrm{m}^{-1}$ for male

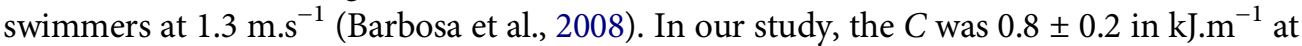
$0.9 \pm 0.1 \mathrm{~m} . \mathrm{s}^{-1}$ for the full sample, $0.7 \pm 0.1 \mathrm{in} \mathrm{kJ.m^{-1 }}$ at $0.9 \pm 0.1 \mathrm{~m} . \mathrm{s}^{-1}$ for female

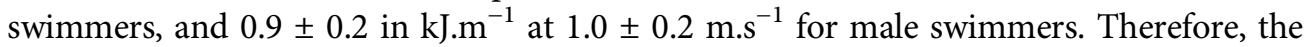
$C$ of swimmers with disabilities appears to be higher than that for non-disabled swimmers, taking swimming speed into account.

To our knowledge, this study is the first to investigate the $\dot{E} t o t$ and $C$ in swimmers with physical impairments. The hypotheses formulated in the introduction were partially accepted. The exception was for the second hypothesis (the Etot and $C$ obtained in $\mathrm{vVO}_{2 \max }$ are higher in swimmers with a higher impacting physical disability). These results can be applied in training and competitions, when coaches are able to determine a swimming series' duration and intensity in an attempt to better achieve the training objectives. The monitoring of the aerobic and anaerobic power achieved along with swimming speed can be used as an important predictor of performance (Ferreira, Barbosa, Costa, Neiva, \& Marinho, 2016; Lacour, Padilla-Magunacelaya, Barthelemy, \& Dormois, 1990). This information can be used in training to simulate the stress levels of competition in the cardiovascular system (Ferreira et al., 2016; Lacour et al., 1990; Roy, Menear, Schmid, Hunter, \& Malone, 2006; Santos et al., 2012).

A small sample of swimmers with physical impairment participated in the current study. This is a limitation that does not enable the extrapolation of the results for all 
populations of swimmers with physical impairments, given the great variability in disabilities and possible interactions with physiological characteristics. Although this study provides useful information in the cases of physical impairment discussed, further investigations can be undertaken with this population in order to extend the set of data.

\section{Conclusion}

The values of $\dot{\mathrm{V}}_{2 \max }$ and $C$ are higher in swimmers with physical impairments that have less of an impact on activity than those with more impact. The $\mathrm{v}_{\mathrm{V}} \mathrm{O}_{2 \max }, \dot{\mathrm{V}} \mathrm{O}_{2 \max }$, $\dot{E}$ tot, and $C$ were higher for the male swimmers with physical impairments than their female counterparts. The aerobic energy contribution was similar for males and females. The main energy contribution was aerobic for both genders, but the anaerobic lactic and alactic pathway contributions differed between male and female swimmers.

\section{Disclosure statement}

No potential conflict of interest was reported by the authors.

\section{ORCID}

Wellington G. Feitosa (ID http://orcid.org/0000-0002-8523-3940

Tiago M. Barbosa (D) http://orcid.org/0000-0001-7071-2116

Ricardo De A. Correia (D) http://orcid.org/0000-0002-2137-2423

Flávio A. De S Castro (D) http://orcid.org/0000-0003-0848-8226

\section{References}

Astrand, P. O., \& Rodahl, K. (1986). Textbook of work physiology. New York: McGraw-Hill.

Barbosa, T. M., Bragada, J. A., Reis, V. M., Marinho, D. A., Carvalho, C., \& Silva, A. J. (2010). Energetics and biomechanics as determining factors of swimming performance: Updating the state of the art. Journal of Science and Medicine in Sport, 13(2), 262-269.

Barbosa, T. M., Fernandes, R. J., Keskinen, K. L., \& Vilas-Boas, J. P. (2008). The influence of stroke mechanics into energy cost of elite swimmers. [Comparative Study]. European Journal of Applied Physiology, 103(2), 139-149.

Bentley, D. J., Phillips, G., McNaughton, L. R., \& Batterham, A. M. (2002). Blood lactate and stroke parameters during front crawl in elite swimmers with disability. Journal of Strength and Conditioning Research, 16(1), 97-102.

Bentley, D. J., Roels, B., Hellard, P., Fauquet, C., Libicz, S., \& Millet, G. P. (2005). Physiological responses during submaximal interval swimming training: Effects of interval duration. Journal of Science and Medicine in Sport, 8(4), 392-402.

Borg, G. (1998). Borg's perceived exertion and pain scales. Champaign: Human Kinetics.

Capelli, C., Pendergast, D., \& Termin, B. (1998). Energetics of swimming at maximal speeds in humans. European Journal of Applied Physiology and Occupational Physiology, 78(5), 385-395.

Chatard, J. C., Lavoie, J. M., \& Lacour, J. R. (1990). Analysis of determinants of swimming economy in front crawl. European Journal of Applied Physiology and Occupational Physiology, 61(1-2), 88-92.

Chatard, J. C., Lavoie, J. M., \& Lacour, J. R. (1991). Energy cost of front-crawl swimming in women. European Journal of Applied Physiology and Occupational Physiology, 63(1), 12-16. 
Conger, S. A., \& Bassett, D. R. (2011). A compendium of energy costs of physical activities for individuals who use manual wheelchairs. Adapted Physical Activity Quarterly: APAQ, 28(4), 310-325.

Costa, M. J., Bragada, J. A., Marinho, D. A., Silva, A. J., \& Barbosa, T. M. (2012). Longitudinal interventions in elite swimming: A systematic review based on energetics, biomechanics, and performance. Journal of Strength and Conditioning Research, 26(7), 2006-2016.

de Souza, H., DA Silva Alves, E., Ortega, L., Silva, A., Esteves, A. M., Schwingel, P. A., ... DE Mello, M. T. (2016). Incremental exercise test for the evaluation of peak oxygen consumption in paralympic swimmers. The Journal of Sports Medicine and Physical Fitness, 56(4), 368-375.

Di Prampero, P. E. (1981). Energetics of muscular exercise. Reviews of Physiology, Biochemistry and Pharmacology, 89, 143-222.

Di Prampero, P. E. (1986). The energy cost of human locomotion on land and in water. International Journal of Sports Medicine, 7(2), 55-72.

Di Prampero, P. E. (2003). Factors limiting maximal performance in humans. European Journal of Applied Physiology, 90(3-4), 420-429.

Di Prampero, P. E., Capelli, C., Pagliaro, P., Antonutto, G., Girardis, M., Zamparo, P., \& Soule, R. G. (1993). Energetics of best performances in middle-distance running. Journal of Applied Physiology: Respiratory, Environmental and Exercise Physiology. [Research Support, Non-U.S. Gov't], 74(5), 2318-2324.

Di Prampero, P. E., Pendergast, D. R., Wilson, D. W., \& Rennie, D. W. (1978). Blood lactic acid concentrations in high velocity swimming. In B. Eriksson \& B. Furberg (Eds.), Swimming medicine IV (pp. 249-261). Baltimore, Md.: University Park Press.

Fernandes, R. J., Billat, V. L., Cruz, A. C., Colaco, P. J., Cardoso, C. S., \& Vilas-Boas, J. P. (2006). Does net energy cost of swimming affect time to exhaustion at the individual's maximal oxygen consumption velocity? The Journal of Sports Medicine and Physical Fitness, 46(3), 373-380.

Fernandes, R. J., Keskinen, K. L., Colaco, P., Querido, A. J., Machado, L. J., Morais, P. A., ... Vilas Boas, J. P. (2008). Time limit at VO2max velocity in elite crawl swimmers. International Journal of Sports Medicine, 29(2), 145-150.

Ferreira, M. I., Barbosa, T. M., Costa, M. J., Neiva, H. P., \& Marinho, D. A. (2016). Energetics, biomechanics, and performance in masters' swimmers: A systematic review. Journal of Strength and Conditioning Research, 30(7), 2069-2081.

Figueiredo, P., Zamparo, P., Sousa, A., Vilas-Boas, J. P., \& Fernandes, R. J. (2011). An energy balance of the $200 \mathrm{~m}$ front crawl race. European Journal of Applied Physiology. [Research Support, Non-U.S. Gov't], 111(5), 767-777. .

Fischer, G., Figueiredo, P., \& Ardigo, L. P. (2015). Physiological performance determinants of a $22-\mathrm{km}$ handbiking time trial. International Journal of Sports Physiology and Performance, 10 (8), 965-971.

Fischer, G., Tarperi, C., George, K., \& Ardigo, L. P. (2014). An exploratory study of respiratory muscle endurance training in high lesion level paraplegic handbike athletes. Clinical Journal of Sport Medicine : Official Journal of the Canadian Academy of Sport Medicine, 24(1), 69-75.

Gonjo, T., McCabe, C., Sousa, A., Ribeiro, J., Fernandes, R. J., Vilas-Boas, J. P., \& Sanders, R. (2018). Differences in kinematics and energy cost between front crawl and backstroke below the anaerobic threshold. European Journal of Applied Physiology, 118(6), 1107-1118.

Grant, S., Craig, I., Wilson, J., \& Aitchison, T. (1997). The relationship between $3 \mathrm{~km}$ running performance and selected physiological variables. Journal of Sports Sciences, 15(4), 403-410.

Howley, E. T., Bassett, D. R., Jr., \& Welch, H. G. (1995). Criteria for maximal oxygen uptake: Review and commentary. Medicine and Science in Sports and Exercise, 27(9), 1292-1301.

International Paralympic Committee [IPC]. (2017). World Para Swimming: Classification rules and regulations. Bonn, Germany: International Paralympic Committee.

Keskinen, K. L., \& Keskinen, O. (1999). Performance test for swimmers - a new approach utilizing pace-maker lights - a pilot study. Gummerus. 245-248. 
Keskinen, K. L., Rodriguez, F. A., \& Keskinen, O. P. (2003). Respiratory snorkel and valve system for breath-by-breath gas analysis in swimming. Scandinavian Journal of Medicine \& Science in Sports, 13(5), 322-329.

Lacour, J. R., Padilla-Magunacelaya, S., Barthelemy, J. C., \& Dormois, D. (1990). The energetics of middle-distance running. European Journal of Applied Physiology and Occupational Physiology, 60(1), 38-43.

Minetti, A. E. (1998). The biomechanics of skipping gaits: A third locomotion paradigm? Proceedings. Biological Sciences / the Royal Society, 265(1402), 1227-1235.

Morris, K. S., Osborne, M. A., Shephard, M. E., Jenkins, D. G., \& Skinner, T. L. (2017). Velocity, oxygen uptake, and metabolic cost of pull, kick, and whole-body swimming. International Journal of Sports Physiology and Performance, 12(8), 1046-1051.

Narang, N., Gore, M. O., Snell, P. G., Ayers, C. R., Lorenzo, S., Carrick-Ranson, G., ... McGuire, D. K. (2012). Accuracy of estimating resting oxygen uptake and implications for hemodynamic assessment. The American Journal of Cardiology, 109(4), 594-598.

Oh, Y. T., Burkett, B., Osborough, C. D., Formosa, D., \& Payton, C. (2013). London 2012 paralympic swimming: Passive drag and the classification system. British Journal of Sports Medicine, 47(13), 838-843.

Ozyener, F., Rossiter, H. B., Ward, S. A., \& Whipp, B. J. (2001). Influence of exercise intensity on the on- and off-transient kinetics of pulmonary oxygen uptake in humans. The Journal of Physiology, 533(Pt 3), 891-902.

Pendergast, C., Capelli, A. B., Craig, P. E., Jr, Di Prampero, A. E., Minetti, J., Mollendorf, A., ... Zamparo, P. (2006). Biophysics in swimming. Revista Portuguesa De Ciências Do Desporto, 6 (2), 185-197.

Pfeiffer, K. A., Pivarnik, J. M., Womack, C. J., Reeves, M. J., \& Malina, R. M. (2002). Reliability and validity of the Borg and OMNI rating of perceived exertion scales in adolescent girls. Medicine and Science in Sports and Exercise, 34(12), 2057-2061.

Poole, D. C., \& Jones, A. M. (2017). Measurement of the maximum oxygen uptake Vo2max: Vo2peak is no longer acceptable. Journal of Applied Physiology, 122(4), 997-1002.

Psycharakis, S. G. (2011). A longitudinal analysis on the validity and reliability of ratings of perceived exertion for elite swimmers. The Journal of Strength and Conditioning Research, 25 (2), 420-426.

Ribeiro, J., Figueiredo, P., Guidetti, L., Alves, F., Toussaint, H., Vilas-Boas, J. P., ... Fernandes, R. J. (2016). AquaTrainer(R) Snorkel does not increase hydrodynamic drag but influences turning time. International Journal of Sports Medicine, 37(4), 324-328.

Ribeiro, J., Figueiredo, P., Sousa, A., Monteiro, J., Pelarigo, J., Vilas-Boas, J. P., ... Fernandes, R. F. (2015). $\mathrm{VO}(2)$ kinetics and metabolic contributions during full and upper body extreme swimming intensity. European Journal of Applied Physiology, 115(5), 1117-1124.

Rodrigues Junior, V., De Jesus, K., Corredeira, R., Daly, D. J., \& Fernandes, R. J. (2016). Physiological characterization of swimmers with physical disabilities. In P. P. Mourouço, N. Batalha, \& R. J. Fernandes (Eds.), Natação e Atividades Aquáticas: Pedagogia, Treino e Investigação (pp. 183-194). Leria, Portugal: Instituto Politécnico de Leiria.

Roy, J. L., Menear, K. S., Schmid, M. M., Hunter, G. R., \& Malone, L. A. (2006). Physiological responses of skilled players during a competitive wheelchair tennis match. Journal of Strength and Conditioning Research, 20(3), 665-671.

Saltin, B., Radegran, G., Koskolou, M. D., \& Roach, R. C. (1998). Skeletal muscle blood flow in humans and its regulation during exercise. Acta Physiologica Scandinavica, 162(3), 421-436.

Santos, T. M., Rodrigues, A. I., Greco, C. C., Marques, A. L., Terra, B. S., \& Oliveira, B. R. R. (2012). Estimated VO2max and its corresponding velocity predict performance of amateur runners. [Athletic performance; Running; Physical fitness]. Rev. Bras. Cineantropom. Desempenho Hum, 14(2), p 10. . 
Sousa, A., Figueiredo, P., Oliveira, N., Oliveira, J., Keskinen, K. L., \& Vilas-Boas, J. P. (2010). Comparasion between VO2peak and VO2max at different time intervals. The Open Sports Sciences Journal, 3, 22-24.

Sousa, A., Vilas-Boas, J. P., \& Fernandes, R. J. (2014). VO2 kinetics and metabolic contributions whilst swimming at 95, 100, and $105 \%$ of the velocity at VO2max. BioMed Research International, 2014, 675363.

Thevelein, X., Daly, D., \& Persyn, U. (1984). Measurement of total energy use in the evaluation of competitive swimmers. In N. Bachl, L. Prakup, \& R. Suckert (Eds.), Current topics in sports medicine (pp. 668-676). Wien: Urban \& Schawarzenerg.

Toussaint, H. M., \& Hollander, A. P. (1994). Energetics of competitive swimming. Implications for training programmes. Sports Medicine, 18(6), 384-405.

Troup, J. (1991). Aerobic characteristics of the four competitive strokes. In T. J. (Ed.), International center for aquatic research annual. Studies by the international center for aquatic research 1990 - 1991 (pp. 3-7). Colorado Spring: US Swimming Press.

Tweedy, S. M., \& Vanlandewijck, Y. C. (2011). International paralympic committee position stand-background and scientific principles of classification in paralympic sport. British Journal of Sports Medicine, 45(4), 259-269.

Wilmore, J. H., \& Costill, D. L. (ed). (2004). Physiology of sport and exercise (3rd ed.). Champaign, IL: Human Kinetics.

Zamparo, P., Antonutto, G., Capelli, C., Francescato, M. P., Girardis, M., Sangoi, R., ... Pendergast, D. R. (1996). Effects of body size, body density, gender and growth on underwater torque. Scandinavian Journal of Medicine \& Science in Sports. [Research Support, Non-U.S. Gov't], 6(5), 273-280.

Zamparo, P., Bonifazi, M., Faina, M., Milan, A., Sardella, F., Schena, F., \& Capelli, C. (2005). Energy cost of swimming of elite long-distance swimmers. European Journal of Applied Physiology. [Clinical TrialControlled Clinical Trial], 94(5-6), 697-704. .

Zamparo, P., Capelli, C., Cautero, M., \& Di Nino, A. (2000). Energy cost of front-crawl swimming at supra-maximal speeds and underwater torque in young swimmers. European Journal of Applied Physiology. [Research Support, Non-U.S. Gov't], 83(6), 487-491. .

Zamparo, P., Capelli, C., \& Pendergast, D. (2011). Energetics of swimming: A historical perspective. European Journal of Applied Physiology. [Historical Article Review], 111(3), 367-378. . 